\title{
Os livros didáticos e o ensino para a saúde: o caso das drogas psicotrópicas *
}

\section{Didactic books and teaching for health: the case of psychotropic drugs}

\author{
Beatriz Carlini-Cotrim** \& Fúlvia Rosemberg***
}

\begin{abstract}
CARLINI-COTRIM, B. \& ROSEMBERG, F. Os livros didáticos e o ensino para a saúde: o caso das drogas psicotrópicos. Rev. Saúde públ., S. Paulo, 25: 299-305, 1991. Foram analisados 18 livros didáticos de primeiro e segundo graus, das disciplinas de Ciências/Biologia, Educação Moral e Cívica e Organização Social e Política do Brasil, em relação ao tratamento dado ao tema consumo de drogas psicotrópicas. A análise da estrutura dos textos evidenciou preocupação excessiva com a discussão dos efeitos (nocivos) das drogas em detrimento de outros tópicos como conceituação, causas que levam ao uso, incidência, tratamento ou prevenção. Os textos se caracterizaram por uma linguagem pouco científica, onde o apelo emocional e o estilo dramático são a tônica. $O$ usuário de drogas foi retratado como sendo necessariamente um ser decadente moral, física e psicologicamente. Os resultados da análise são discutidos à luz de teorias recentes de prevenção ao abuso de drogas.
\end{abstract}

Descritores: Livros de texto. Psicotrópicos. Educação em saúde.

\section{Introduçáo}

O livro didático parece se constituir, para o professorado brasileiro, no principal veículo de informação da matéria que leciona. Freitag e $\mathrm{col}^{5}$ são enfáticos a este respeito. Depois de analisarem pesquisas brasileiras sobre o livro didático no cotidiano de professores afirmam: "o livro didático não funciona em sala de aula como instrumento auxiliar para conduzir o processo de ensino e transmissão do conhecimento, mas como modelo-padrão, a autoridade absoluta, o critério último da verdade. Neste sentido, os livros parecem estar modelando os professores. $O$ conteúdo ideológico do livro é absorvido pelo professor e repassado ao aluno de forma acrítica e não distanciada".

Por outro lado, os livros didáticos se constituem praticamente no único material impresso de que muitos alunos brasileiros dispõem (Fundação IBGE 6 , 1982), e o próprio Estado tem, nas últimas

* Subvencionado pela Fundação de Amparo à Pesquisa do Estado de São Paulo (Processo 88/3448-9) e United Nation Fund for Drug Abuse Control (UNFDAC).

* Centro Brasileiro de Informaçōes sobre Drogas Psicotrópicas da Escola Paulista de Medicina e da Pontifícia Universidade Católica de São Paulo - São Paulo, SP . Brasil.

*** Fundação Carlos Chagas e Pontifícia Universidade Católica de São Paulo, SP - Brasil.

Separatas/Reprints: B.C.Cotrim - Depto. de Psicobiologia - Rua Botucatu, 862 - 04023 - São Paulo, SP . Brasil.

Publicação financiada pela FAPESP. Processo 90/4602-1. décadas, comprado e distribuído em massa esses livros, reforçando ainda mais a prática de centrar o cotidiano de ensino nesse material.

Assim sendo, o conteúdo veiculado pelos livros didáticos parece ser um componente importante na análise da situação do ensino em nosso país.

De fato, um grande número de pesquisas nacionais tem se dedicado a analisar o conteúdo desse material ${ }^{5}$. Na área específica de educação para a saúde, abordada atualmente dentro das Ciências e Biologia, a produção é escassa. Particularmente em relação ao tema consumo de drogas, nada existe a respeito.

$O$ presente trabalho analisa livros didáticos de primeiro e segundo graus quanto ao conteúdo que transmitem sobre drogas psicotrópicas, procurando assim contribuir para a elaboração de estratégias educacionais adequadas para a abordagem deste tópico, tão evidenciado nos últimos anos.

\section{Material e Método}

\section{A escolha da amostra}

Foram analisados 18 livros didáticos das áreas de ciências biologia e organização social e política do Brasil (OSPB)/educação moral e cívica (EMC). Tal opção se deu pelo estatuto ambiguo do tema que nos interessa: apesar de se tratar de um assunto do âmbito das Ciências (fato reforçado pela Lei de Entorpecentes n. 6368/76 e pelos Guias Curriculares), é revestido, em nossa sociedade, de um forte componente moral, o que adequaria a sua inclusão na área de educação moral e cívica. 
Os livros analisados foram selecionados através de levantamento efetuado junto às editoras especializadas.

Estas foram selecionadas em função de dois critérios:

a) constar como sendo uma das dez maiores editoras de livros didáticos do país na lista "As cem maiores de 87 ", publicada na revista $L E I A\left(n^{2}\right.$ 22 , junho de 1988), classificação resultante de ampla pesquisa sobre as editoras brasileiras promovida por aquele periódico. As editoras estão classificadas na citada lista em ordem decrescente de quantidade de títulos publicados e divididas por especialidade (Literatura Brasileira, Paradidáticos, Variedades, Didáticos, entre outras);

b) editar livro que conste do "Relatório dos 10 Títulos mais adotados por Série, em São Paulo", na área de ciências, organizado pela Fundação de Assistência ao Livro Escolar (FAE). Este relatório divulgou os títulos mais solicitados pelos professores para serem doados às escolas públicas de primeiro e segundo graus pelo Ministério da Educação/FAE, através do Programa Nacional do Livro Didático, em 1987/88. As disciplinas de EMC e OSPB não integram cste programa, por isso não constam da lista.

As editoras localizadas em São Paulo foram visitadas pessoalmente, durante o ano de 1988 , na seção de atendimento a professores ou de divulgação de material. As visitas foram formalizadas por ofício, ao Centro Brasileiro de Informações sobre Drogas Psicotrópicas, da Escola Paulista de Medicina, solicitando o acesso a todos os livros editados, em circulação, das áreas de ciências e ECM/OSPB. Os livros existentes foram cuidadosamente folheados no sentido de localizar textos, capítulos ou citações que abordassem 0 assunto drogas, incluindo-se nesta definição os medicamentos, o álcool, o tabaco e as drogas ilícitas. Quando se localizava um desses assuntos, os livros eram na maioria das vezes doados.

Na Tabela 1, cncontra-se a indicação das Editoras pesquisadas, o númcro total de publicações consultadas nas áreas de ciências e OSPB, assim como a proporção de livros com capítulos ou textos auxiliares onde o tema drogas é tratado. A lista completa dos livros que compõem a análise estão relacionados no Anexo.

\section{Análise dos textos}

Os livros didáticos são formados por um conjunto de lições que recortam e delimitam o programa da disciplina. Assim, procuramos identificar a presença do tema drogas nas diferentes liçðes. Obscrvamos que os livros de uma dada disciplina só tratam do
Tabela 1. Livros didáticos consultados, nas áreas de OSPB* e Ciências, e proporção destes que abordam a questão de drogas em seu conteúdo, segundo a editora.

\begin{tabular}{lcccr}
\hline & $\begin{array}{c}\text { Livros consultados } \\
\text { com tema drogas }\end{array}$ & \multicolumn{2}{l}{ Total } \\
Editora** & OSPB Ciências & OSPB Ciencias \\
\hline Ática & 2 & 2 & 4 & 18 \\
Atual & 0 & 1 & 1 & 10 \\
Brasil & 0 & 1 & 1 & 8 \\
FTD & 0 & 1 & 2 & 6 \\
Globo & 0 & 0 & 2 & 2 \\
IBEP/Nacional & 0 & 3 & 2 & 33 \\
Loyola & 0 & 0 & 0 & 0 \\
Moderna & 0 & 1 & 1 & 9 \\
Record & 0 & 1 & 1 & 1 \\
Saraiva & 3 & 2 & 8 & 9 \\
Scipione & 0 & 1 & 0 & 11 \\
Vozes & 0 & 0 & 0 & 0 \\
\hline Total N & 5 & 13 & 22 & 107 \\
& & & & 100 \\
\hline \multicolumn{1}{c}{$\%$} & 23 & 12 & 100 & 100 \\
\hline
\end{tabular}

* Organização Social e Política do Brasil

* Localizados no município de São Paulo, com exceção da Ed. Record, que atendeu à solicitação, enviando os livros sobre os temas pesquisados.

tcma em determinados capítulos, o que facilitou a análise, mas também indicam a forma fragmentada pela qual se transmitem conhecimentos científicos.

Foram utilizadas técnicas de "análise de conteúdo"1 para a discussão dos capítulos em que o tema era tratado. Estes foram, primeiramente, objeto de uma "leitura flutuante" ${ }^{\text {"1 }}$ para definição das categorias de análise. Duas unidades de conteúdo pareceram ser as mais pertinentes: a estrutura de transmissão da informação e o estilo do texto.

A primeira procurou detectar e descrever os componentes que compõem a informação veiculada sobre drogas. Seus componentes foram: conceito (de drogas), incidência (do uso), causas (que explicam o uso), efeitos (do uso) e prevenção (ao uso). A preocupação foi constatar a presença/ausência da categoria bem como a forma de seu tratamento textual.

A segunda unidade foi construida empiricamente, orientada pelas posturas que indicam a prevenção ao abuso de drogas ${ }^{3}$. Detectamos um estilo afetivo/emocional em contraposição, principalmente nos livros de ciências/biologia, a uma expectativa teórica de cientificidade. Para objetivar esta aprecnsão globalizante, analisamos a linguagem que o texto usa e o tratamento que dá à informação cicntílica. 


\section{Resultados}

\section{Apresentação geral}

Do total dos livros consultados, 25 capítulos são dedicados ao tema ou o mencionam. Os livros tanto tratam em um mesmo capitulo do álcool, tabaco e outras drogas ("Os perigos dos tóxicos do álcool e do fumo") quanto dedicam capítulos em separado às toxicomanias, alcoolismo e tabagismo. Álcool e tabaco recebem tratamento especial, sendo-lhes dedicados maior número de capítulos, constituindo mesmo, em alguns poucos livros (principalmente os de ciências), as únicas drogas tratadas.

A inserção desse tema no livro ocorre de acordo com a disciplina. Em ciências, a questão aparece incluída nos capítulos sobre sistema respiratório (tabaco), digestivo (álcool) ou sistema nervoso (álcool e outras drogas). Pode-se encontrar também uma inserção no capítulo referente ao aparelho reprodutor. A associação entre drogas e sexo ocorre, sobretudo, na informação sobre os efeitos. Em EMC e OSPB o tema aparece no capítulo sobre "caráter, hábitos, virtudes e vícios", tratando, portanto, do uso na perspectiva do vício ou dependência.

Dezesseis drogas psicotrópicas foram abordadas. Tabaco e álcool são as mais mencionadas, seguidas de maconha, cocaína, heroína, morfina e ópio (Tabela 2). Tal hierarquia de preocupação contrasta vivamente com a distribuição epidemiológica do consumo de drogas na população estudantil brasileira. De fato, o tabaco e álcool são as drogas mais usadas pelos estudantes; já a maconha aparece em quinto ou sex-

Tabela 2. Substâncias psicotrópicas abordadas em livros didáticos de ciências/biologia e educação moral e civical OSPB* (Total de livros pesquisados $=18$ ).

\begin{tabular}{cc}
\hline Psicotrópicos & $N^{2}$ de abordagens \\
\hline Tabaco & 16 \\
Álcool & 15 \\
Maconha & 13 \\
Cocaina & 12 \\
Heroína & 10 \\
Morfina & 10 \\
Ópio & 8 \\
LSD & 8 \\
Anfetaminas & 5 \\
Mescalina & 5 \\
Tranquilizantes & 3 \\
Psilocibina & 3 \\
Codeina & 3 \\
Barbitúricos & 3 \\
Cafeina & 2 \\
Inalantes & 2 \\
\hline
\end{tabular}

- Organização Social e Política do Brasil to lugares, o consumo de cocaína não chega a $1 \%$ e não há relatos, nessa população, de uso de heroína, morfina e ópio ${ }^{2}$.

Já os inalantes, os tranqüilizantes e as anfetaminas, as três drogas mais usadas pela população estudantil brasileira, excetuando álcool e tabaco ${ }^{2}$, são mencionadas somente em dois, três e cinco livros, respectivamente (Tabela 2 ).

\section{Estrutura e estilo}

Os textos - tanto em sua estrutura quanto no estilo - são regidos por dois eixos complementares: adotam a pedagogia do amedrontamento e se organizam em torno do conceito implícito de dependência (e não do uso) de drogas. Assim, a despeito de grande parte deles pertencer a disciplinas científicas, a informação organiza-se visando a um impacto possível no leitor, pelo amedrontamento. Ao invés de se transmitirem precisōes conceituais, dados sobre incidência, análise das causas e orientações para prevenção e tratamento, ocorre uma hipertrofia do efeito do uso de drogas, mais especialmente de sua dependência(Tabela 3). Neste caso, pouco cuidado se tem com as informações objetivas, como o conceito ou a classificação das drogas. Foi possível ler que "o alcoolismo é um termo usado para denominar os efeitos das bebidas alcóolicas sobre o organismo" (Anexo, referência 12, p.48) ou que "o álcool etílico, o ópio e a cocaína seriam drogas euforizantes" (Anexo, referência 12, p.42).

Os efeitos (categoria mais frequiente) são múltiplos e geridos quase sempre pela lei do tudo ou nada, tratados de forma genérica, sem que haja uma especificação de dose, padrão de uso ou tipo de droga.

Esta generalização é a base de um texto onde a loucura, a morte, a cegueira e a despersonalização aparecem como uma possibilidade eminente para qualquer usuário de droga.

"No início, as drogas provocam euforia e um estado agradávcl, mas logo depois vêm as conseqüências nocivas: depressão, alucinações auditivas e visuais, paranóia, agressividade (levando a crimes). Acarretam

Tabela 3. Estrutura da informação sobre drogas psicotrópicas em dezoito livros didáticos das áreas de ciências/biologia e educação moral e cívica/OSPB*.

\begin{tabular}{cc}
\hline Estrutura da Informação & No de Abordagens \\
\hline Conceito & 13 \\
Classificação & 6 \\
Causa & 7 \\
Efeito & 18 \\
Prevenção & 12 \\
Incidência & 9 \\
Tratamento & 3 \\
\hline
\end{tabular}

* Organização Social e Política do Brasil 
também a degeneração física, que leva à morte por meio de: ataque cardíaco, coma, hemorragia cerebral e outras." (Anexo, referência 11, p.23).

"Cada droga em particular tem efeitos próprios, mas podemos sistematizar alguns efeitos gerais:

- alteraçð̃es do sistema nervoso central: os psicotrópicos agridem o sistema nervoso central causando alterações físicas e mentais;

- alterações sexuais: inicialmente, por ação psíquica, as drogas produzem exacerbação da libido. Com o tempo, porém, há diminuição do poder de execução do ato sexual; - desequilíbrio orgânico: o uso de drogas afeta todas as partes do organismo. Promove alterações respiratórias, circulatórias, digestivas, glandulares e urogenitais. O viciado com o tempo adquire aspecto próprio, tornando-se pálido, com os olhos esbugalhados, pálpebras empapuçadas e sinais de envelhecimento precoce;

- confusão e desagregação mental: no início, o viciado experimenta excitação da memória e aclaramento de idéias e isso o anima a continuar. Mais tarde aparece obnubilação mental, apatia psíquica, embotamento, idiotia e psicoses." (Anexo, referência 12, p.41). "Cada tóxico causa o seu próprio efeito. No entanto, de um modo geral, todos provocam alguns efeitos semelhantes, como, por exemplo: alterações mentais, incapacidade para a vida sexual, alteraçōes respiratórias, circulatórias, digestivas e grandulares, envelhecimento rápido, desagregação mental, desajuste social e psicoses." (Anexo, referência 9, p.160).

A lei do tudo ou nada se reflete, também, numa visão de inexorabilidade do percurso do usuário pois os livros transmitem, de modo geral, uma visão de que o contato com drogas leva, necessariamente, à dependência. Não há espaço para o uso eventual, recreativo, terapêutico, ou mesmo um abuso com problemas, mas sem dependência.

Fica difícil saber porque as pessoas usam drogas, havendo um hiato na explicação. $O$ recurso ao conceito de dependência é o elo que permite tratar do efeito sem discutir o prazer buscado. Há, possivelmente, medo de que a transmissão de certas informações abra caminho à curiosidade do jovem. E a figura do jovem aparece na construção do discurso como sendo o outro elo que permite reestabelecer a lógica (externa) da explicação do uso (sempre visto como início de dependência): ele é ingênuo, curioso e influenciável; é uma presa fácil para traficantes inescrupulosos.
"Três são as fases que descrevem o caminho do vício. Primeiramente, é a fase da tolerância, quando o organismo está se adaptando à droga; depois é a fase do hábito, em que o indivíduo passa a necessitar da droga, tanto psicológica como emocionalmente; finalmente, chega a última fase: a dependência." (Anexo, referência 2, p.141).

"Cadáveres e moribundos de 18 ou 20 anos são encontrados nas calçadas de qualquer cidade. São aqueles que alguns meses passados, atendendo a criminosos convites de traficantes, aceitaram o primeiro contato com o vício". (Anexo, referência 1, p.144).

"O vício do uso de tóxicos geralmente é adquirido em fases bem distintas: inicialmente, em doses pequenas, $o$ indivíduo acostuma-se ao uso da droga, depois passa a sentir necessidade dela $e$, finalmente, torna-se um dependente." (Anexo, referência 9, p.160).

Pelo fato de a juventude se constituir em fase da vida muito centrada na sexualidade, a pedagogia do amedrontamento associa com frequiência droga e sexo, mesmo que para isto seja necessário transmitir informações incorretas.

"Pesquisas recentes, feitas com fumantes habituais de maconha, indicam uma diminuição no número de espermatozóides e na produção de hormônio masculino, o que pode levar à impotência sexual." (Anexo, referência $17, \mathrm{p} .152$ ).

A incidência é tratada de modo impreciso. Há um intuito, no geral, de conferir cientificidade aos textos, seja pelo uso freqüente de expressðes como "a ciência informa" ou "está cientificamente comprovado", seja pela legitimidade de entidades internacionais que usufruem da fama de idoneidade e competência, como a Organização Mundial de Saúde. Porém, quando se atenta para as informações sobre incidência, observa-se que são apenas qualitativas, gerando um tom alarmista, predominando a visão de que o consumo de psicotrópicos vem crescendo dia-a-dia. Aqui, mais uma vez, o texto oscila entre a dependência e o uso: naqucle os números são pequenos, mas os efeitos alarmantes; neste, os números já são suficientes para o alarme.

"O consumo de drogas tem crescido assustadoramente em todo mundo..." (Anexo, referência 12, p.45).

"Só no Brasil o tabaco mata cerca de 15 pessoas por hora e deixa outras tantas enfermas" (Anexo, referência 5, p.33).

"De acordo com uma pesquisa da Organização Mundial da Saúde, morrem no mundo anualmente cerca de um milhão de pessoas por causa do consumo de cigarros" (Anexo, 
referência 4, p.19).

"Como reconhece a própria OMS, o consumo de drogas, no agitado mundo moderno, vai ganhando dimensōes assustadoras" (Anexo, referência 6, p.109).

"Diariamente, dois menores morrem em Nova York por excesso de heroína" (Anexo, referência 1, p.144).

No campo da prevençāo, predomina o tom claramente normativo. Para evitar o "vício das drogas", o jovem deve ingerir alimentos ricos e variados, praticar esporte, dedicar-se à leitura, repousar, evitar más companhias, ter diversões sadias, não ser preguiçoso, egoísta ou medroso. Uma publicação citada no Anexo (referência 1) recomenda, neste tópico, que se evite a masturbação. Somente dois livros falam da prevenção através do oferecimento de "opções sociais" e de se "combater as injustiças" (Anexo, referência 17,), ou de "se lutar por uma sociedade sadia, onde o valor das pessoas esteja em primeiro lugar" (Anexo, referência 5).

Contribuindo para o tom de alarme, os livros criam um clima dramático, usando adjetivação superlativa.

"... Os tóxicos são substâncias que atuam sobre o sistema nervosos central, provocando alteraçōes NOCIVAS no comportamento.. ( ) A dependência é TERRÍVEL...( )... tornando o viciado um indivíduo INCONSCIENTE E PERIGOSO..." (Anexo, referência 8, p.160-1).

"Elas (as drogas estimulantes) provocam na pessoa um estado inicial de agitação e bemestar que é mais tarde seguido de angústia GRAVE, TERRÍVEL mal-estar, desespero e depressão" (...) Sobre as drogas perturbadoras: "causando no individuo sensações que tanto podem ir de um estado de leveza até HORRIPILANTES visões, MONSTRUOSAS E APAVORANTES". (Anexo, referência 16, p.104).

"O viciado torna-se PÁlIDO, com olhos ESBUGALHADOS e sinais de envelhecimento PRECOCE... Com o decorrer do tempo, torna-se APÁTICO, CONFUSO, chegando até a idiotia..." (Anexo, Referência 2, p.142).

\section{Ilustrações}

A grande maioria dos livros é fartamente ilustrada, com desenhos ou fotos, algumas vezes coloridas. Há, em alguns deles, uma preocupação com a diagramação, tornando o livro semelhante, graficamente, a uma revista. Títulos, chamadas, boxes são outros recursos gráficos que, visivelmente, foram empregados para impregnar os li- vros de um tom moderno. Os livros da área de saúde se destacam graficamente dos demais: assumem o formato de manual e suas ilustrações não são em cores.

As ilustrações relativas às drogas apresentam algumas particularidades: em sua maioria, referem-se ao tabaco e logo em seguida ao álcool, sendo que as demais recebem ilustração em apenas três livros (Tabela 4).

Tabela 4. Ilustraçōes de livros didáticos de ciências/ biologia e educação moral e cívica/OSPB* em relação a drogas psicotrópicas.

\begin{tabular}{ccc}
\hline Drogas Abordadas & N2 de llustrações & $N^{2}$ de Livros \\
\hline Tabaco & 20 & 10 \\
Álcool & 7 & 6 \\
Outros & 7 & 3 \\
Genérico & 6 & 5 \\
\hline
\end{tabular}

* Organização Social e Política do Brasil

A quase totalidade das ilustrações que contém figuras humanas representam homens, sendo que mulheres aparecem apenas fumando (uma vez), em situações genéricas (uma vez) ou em contra - exemplos ao "vício das drogas". O sexo feminino é, assim, menos encontrado aqui do que na literatura destinada a criança e jovens de uma maneira geral, onde a mulher aparece em um terço das ilustrações ${ }^{7}$.

O tema predominante nas ilustrações é a morte: caveiras, esqueletos (parciais ou completos) e túmulos. Mesmo quando a morte está ausente, o clima da ilustração é sombrio e desolador. Homens com barba por fazer, correntes que os atrelam, labirintos e fundos escuros conferem, juntamente com a morte, o clima de degradação social e moral que se quer associar ao uso de drogas.

Apenas dois livros utilizam a ilustração para divulgar cartazes de campanhas anti-tabagismo realizadas no Brasil e no exterior, o que confere a essas páginas um tom menos lúgubre.

\section{Discussão}

É desnecessário, porque óbvio, afirmar que o material analisado situa-se, em sua grande maioria, na perspectiva dos modelos preventivos de amedrontamento e do princípio moral ${ }^{3}$.

Parte-se, nos livros didáticos, da premissa de que praticar a "pedagogia do terror" é uma estratégia eficiente do ponto de vista preventivo. Para isso, tudo é válido: fazer afirmações cientificamente infundadas e abstrair o retrato epidemiológico do país. Ignoram-se, assim, resultados de 
décadas de pesquisa no campo da educação sobre 0 consumo de psicotrópicos ${ }^{3}$ que apontam a ineficiência desses modelos, ou até seu efeito paradoxal, gerando muitas vezes um incremento do abuso dessas substâncias.

Este anacronismo teórico é tão intenso que dá espaço a uma questão: será que o objetivo último nesses textos é evitar o abuso de drogas? Esta pergunta torna-se mais pertinente quando se atenta para a assimilação entre o uso e a dependência: o uso guiaria a avaliação da incidência e a dependência a avaliação do impacto.

O que mais causa impacto nos textos analisados é a abstração do fato que a droga pode propiciar prazer (na forma de sensações gostosas ou de alívio de sensações ruins). Ao negar esta possibilidade, passa-se a contar somente com a ingenuidade como categoria explicativa. Dentro desta lógica, é a ingenuidade que faz com que o adolescente ceda à curiosidade, à pressão de grupo ou à oferta do traficante e, hipoteticamente, evite o uso de drogas com a argumentação contida nos livros.

A decorrência disto é um rol de recomendaç̃es e normas que os "indefesos jovens de nosso país" devem observar para não se transformarem em "farrapos humanos" (expressão usada nas referências 5, 8, 16 - Anexo). Nesta medida, o controle do adulto sobre o jovem legitima-se - há maior legitimidade que evitar a morte de um jovem? - e, mais uma vez, a produção de textos visando ao público infanto-juvenil afirma sua missão normatizadora e moralizadora?

Neste quadro, faz sentido que o uso de drogas na forma de medicamentos psicotrópicos (tranqüilizantes e anfetaminas, principalmente) seja raramente abordado, apesar de sua grande difusão entre estudantes. Essas substâncias estão bem menos associadas a um comportamento adolescente, sendo inclusive muito abusadas pelos adultos.

Com esses ingredientes todos, a apropriação das drogas como um dos elementos de uma subcultura jovem, em contraposição ao mundo adulto, se reproduz e se fortalece. $E$ os problemas associados ao uso crônico ou mesmo agudo das substâncias psicotrópicas, que evidentemente existem e não são poucos, acabam por se perpetuar.

Concluindo, os dados do presente trabalho apontam para a importância de se analisarem os conteúdos e as práticas desenvolvidos no cotidiano escolar ${ }^{4}$ em relação às drogas para, a partir deste conhecimento, propor políticas públicas no setor. Tentar, por exemplo, reciclar autores e editores dos livros didáticos brasileiros, em relação a este assunto, poderia ser uma medida pertinente e que talvez pudesse alcançar algum resultado no sentido de uma abordagem mais adequada do tema. Principalmente quando se atenta para o fato de que é o Estado o maior comprador de livros didáticos do país.

CARLINI-COTRIM, B. \& ROSEMBERG, F. [Didactic books and teaching for health the case of psychotropic drugs].Rev. Saúde públ., S. Paulo, 25: 299-305, 1991. Eighteen didactic books on Sciences/Biology, Civic and Moral Education and Brazilian Political and Social Studies, for primary and secondary schools, were analyzed, with a view to assessing the way in which the issue of psychotropic drug use is dealt with. The texts analyzed are structurally centered on the discussion of the harmful effects of drugs instead of discussing others topics (such as etiology, concepts, treatment, incidence and prevalence). The texts are characterized especially by the use of non-scientific language in which emotional appeal and an exceedingly exacerbated style are the rule. The drug user is described as being necessarily a moral, physical and psychological decadent. The results were discussed in the light of recent theories on the prevention of drug abuse.

Keywords: Textbooks. Psychotropic drugs. Health education.

\section{Referências Bibllográficas}

1. BARDIN, L. Análise de conteúdo. Lisboa, Ediçôes 70 , 1977.

2. CARLINI, E. A.; CARLINT-COTRIM, B.; SILVA-FILHO, A. R,; BARBOSA, M.T.S. II levantamento nacional sobre o uso de psicotrópicos em esiudantes de lo. e 20. graus, 1989. São Paulo, CEBRID. Escola Paulista de Medicina, 1990.

3. CARLINI-COTRIM, B. \& PINSKY, I. Prevenção ao abuso de drogas na escola: uma revisão da literatura internacional recente.Cad. Pesq., 69: 48-52, 1989.

4. CARLINI-COTRIM, B. \& ROSEMBERG, F. Drogas: prevenção no cotidiano escolar. Cad. Pesq., 74: 40-6, 1990.

5. FREITAG, B.; MOTTA, V. R.; COSTA, W.F. O estado da arie do livro didático no Brasil. Brasília, INEP, 1987.

6. FUNDAÇÃO INSTITUTO BRASILEIRO DE GEOGRAIIA E ESTATISTICA. Pesquisa nacional por amostra de domicilio (PNAD). Rio de Janeiro, 1982.

7. ROSEMBERG, F. Literatura infantil e ideologia. São Paulo, Global, 1985.

Recebido para publicaçẫo em 12/11/1990 Aprovado para publicaçäo em 29/5/1991

\section{Anexo}

Bibliografia dos livros didáticos pesquisados

1. ANDRADE FILHO, J.H. Programas de saúde: paz, amor, saúde. Rio de Janeiro, Record, 1984.

2. ANDREOLLI, F. Ciências: corpo humano. São Paulo, Ed. do Brasil, 1988.

3. BARROS, C. O corpo humano: programas de saúde. $27^{\mathrm{a}}$ ed. São Paulo, Ática, 1987.

4. CORREA, A.A. Educação moral e cívica. $27^{\mathbf{a}}$ ed. São Paulo, Ática, 1988. v. 1.

5. CORREA, A.A. Educação moral e cívica. $19^{2}$ ed. São Paulo, Ática, 1988. v. 2.

6. COTRIM, G.V. Educação moral e cívica: para uma geraçẩo consciente. $8^{\mathbf{a}}$ ed. São Paulo, Saraiva, 1988. 
7. GOWDAK, D. Biologia. Ecologia. São Paulo, FTD, s.d.

8. LOPES, P.C. O corpo humano: ciências e saúde. $7^{7} \mathrm{ed}$. São Paulo, Saraiva, 1987.

9. LOPES, P.C. Ciência e saúde. São Paulo, Saraiva, s.d.

10. LUCCI, E. Educação moral e cívica. São Paulo, Saraiva, s.d., v.1.

11. LUCCI, E. Educação moral e civica. São Paulo, Saraiva, s.d., v.2.

12. MARCONDES, A.C. Programas de saúde. São Paulo, Atual, 1983.

13. OLIVEIRA, E.C. Ciência e vida. São Paulo, IBEP, s.d.

14. PORTO, D.P. \& MARQUES, J.L. Ciências: o corpo humano. São Paulo, Scipione, 1988.
15. SARTORI, J.; MARQUES, J.; MARQUES, J. Iniciação científica. São Paulo, IBEP, 1988.

16. SOARES, J.L. Ciências: o corpo humano. $2^{\sharp}$ ed. São Paulo, Modema, 1985.

17. VASCONCELLOS, J.L. \& GEWANDSZNAJDER, F. Programas de saúde. São Paulo, Ática, 1989.

18. ZEINUM, R. Ciências, corpo humano: saúde-ecologia. São Paulo, IBEP, s.d.

Recebido para publicação em 12/11/1990 Reapresentado em 28/05/1991 Aprovado para publicaçāo em 05/06/1991 